WE DANCE ROUND IN A RING AND SUPPOSE, BUT THE SECRET SITS IN THE MIDDLE AND KNOWS.

\title{
FROM ANTITUBULINS TO TRACKINS
}

\author{
Stanislav Yanev ${ }^{1}$, Marco Fiore ${ }^{2}$, Alexander Hinev ${ }^{3}$, Peter I. Ghenev ${ }^{4}$ Mariyana G. Hristova ${ }^{5}$, \\ Plamen Panayotov 6 , Anton B. Tonchev ${ }^{7}$, Nikolay Evtimov ${ }^{8}$, Luigi Aloe ${ }^{2}$, and George N. Chaldakov \\ ${ }^{1}$ Department of Drug Toxicology, Institute of Neurobiology, Bulgarian Academy of Sciences, Sofia, \\ Bulgaria, ${ }^{2}$ Institute of Cell Biology and Neurobiology, National Research Council (CNR), Rome, Italy, \\ ${ }^{3}$ Department of Urology, University St Marina Hospital, Varna, Bulgaria, ${ }^{4}$ Department of Pathology, \\ Medical University, Varna, Bulgaria, ${ }^{5}$ Endocrinology Unit, Asparuhovo Polyclinic, Varna, Bulgaria, \\ ${ }^{6}$ Department of Cardiac Surgery, University St Marina Hospital, Varna, Bulgaria, ${ }^{7}$ Department of \\ Anatomy and Histology, Medical University, Varna, Bulgaria, ${ }^{8}$ Urology Clinic, St Anna Hospital, Varna, \\ Bulgaria, and ${ }^{7}$ Laboratory of Cell Biology, Department of Anatomy and Histology, Medical University, \\ Varna, Bulgaria
}

\begin{abstract}
Microtubules (MT) are dynamically instable, assembling and disassembling structures of the cell. Tubulin, the major building protein of MT, is a heterodimer consisting of $\alpha$ and $\beta$ subunits. Agents that bind to tubulin and inhibit its assembly lead to the inhibition of MT formation. Such tubulin-binding agents are usually termed MT-disassembling agents or antitubulins. Endocytosis, matrix protein secretion, cell division, cell migration and inflammation are examples of MT-dependent processes. Their dysfunction, in particular in arterial smooth muscle cells (ASMC), is critically involved in atherogenesis. Here we Dance round (i) MT-based secretory pathway in ASMC and, in turn, antitubulins for atherosclerosis therapy, and (ii) the neurotrophins, particularly nerve growth factor (NGF) and brain-derived neurotrophic factor (BDNF) and their receptors Trk (tyrosine receptor kinase; pronounced "track"), introducing the term trackins - Trk-targeting agents (TTA) that influence positively (agonistically) or negatively (antagonistically) the activity of TrkA receptor for NGF and/or TrkB receptor for BDNF. We propose that some trackins and their native ligands may have therapeutic potentials for cardiometabolic, neuropsychiatric, oncologic and other diseases. Finally the interaction of MT-tubulin and neurotrophin Trk receptors is outlined.
\end{abstract}

Biomed Rev 2016, 27: 59-67

Key words: microtubules, tubulin, colchicine, NGF, TrkA, BDNF, TrkB, disease

Received 29 November 2016, revised 14 December 2016, accepted 15 December 2016.

Correspondence to Dr George N. Chaldakov, Laboratory of Cell Biology, Department of Anatomy and Histology, Medical University, BG-9002 Varna, Bulgaria E-mail: chaldakov@yahoo.com 


\section{ANTITUBULINS}

\section{Microtubules are multifunctional structures}

The cytoskeleton is composed of actin filaments, intermediate filaments and microtubules (MT). At the molecular level, the cytoskeleton is composed of $(i)$ actin, myosin, spectrin, titin, septin, dystrophin, desmin, vimentin, keratin, lamin and other filaments and more than hundred associated proteins, and (ii) MT and microtubule-associated proteins (MAP1, 2, 4, 6, 7, tau proteins, kinesins, dynein, etc) (1).

Microtubules are 25-nm tubule-like structures formed by $\alpha, \beta$-tubulin heterodimers to which GTP, MAP and motor proteins bind. They are polar structures having fast-growing plus end and slow-growing minus end. For the mechanobiology of membrane-bound organelles as well as chromosomes in mitotic spindle, MT work in tandem with the motor proteins (i) kinesin (a MT-activated adenosine triphosphatase, an anterograde, plus end-directed motor), and (ii) dynein (another MT-activated ATPase, a retrograde, minus end-directed motor). There are many publications for kinesin and dynein superfamily, one of these by Nobutaka Hirokawa, a leading scientist in the field (2). The bidirectional cargo movement is frequently described as a tug-of-war between oppositely acting molecular motors attached to the same cargo (3-5).

In brief, MT control multiple cell functions including endocytosis, matrix protein secretion, cell division, cell migration and inflammation, their dysfunction being involved in the process of atherogenesis $(6,7)$. Owing to these reasons, tubulin and MT have gained significant interest as important targets for atherosclerosis therapy.

\section{Microtubules and secretory pathway in arterial smooth muscle cells}

The arterial smooth muscle cells (ASMC) are capable of modulation from contractile to secretory phenotype related to the synthesis and release of matrix molecules (e.g. procollagens, proelastin, fibrillin, proteoglycans, glycosaminoglycans) as well as cytokines and growth factors. The long-standing Russell Ross' response-to-injury paradigm (6) stated that proliferation, migration and secretory activities of ASMC are determinantly implicated in the formation of atherosclerotic plaques.

As discussed in George E. Palade lecture published in this volume of Biomedical Reviews (8), two of us (GNC, PG), using electron microscopy, had studied the structures involved in secretory process of ASMC with special reference to (i) Golgi complex-derived secretion granules, and (ii) cytoplasmic MT.
The possible role of MT for transport of secretion granules was examined in rabbits treated with a sub-antimitotic dose of colchicine, a classical antitubulin (MT-disassembling agent). Colchicine treatment resulted in (i) disappearance of MT, and (ii) accumulation of Golgi-derived secretion granules, suggestive of inhibition of exocytosis of secretory granules, the final step of secretory pathway of ASMC (8-10).

\section{Tubulin: target for atherosclerosis therapy}

Any drug found to inhibit net collagen secretion and/or stimulate collagen degradation selectively might potentially be useful in the therapy of atherosclerosis, a fibroproliferative vascular disease $(6,7,11)$. We will discuss later why and how this paradigm was shifted.

As reported by other colleagues, histological examination showed that patients with scleroderma and with liver cirrhosis receiving colchicine (1 mg/day) had decreased dermal and liver collagen respectively. Since the net collagen production is dependent on both secretion and degradation of collagen, it should be kept in mind that MT and kinesin in ASMC are also involved in the formation of podosomes, cell protrusions engaged in collagen breakdown (12).

More than 100 years ago colchicine was extracted from Colchicum autumnale (autumn crocus). In fact, the therapeutic action of Colchicum extract has been experienced for gouty arthritis hundred years BC. Colchicine is a prototypic example of agents that exert a high affinity binding to the $\boldsymbol{\beta}$-subunit of tubulin dimer, thus leading to MT disassembly. Correspondingly, these agents were dubbed antitubulins or MT disassembling agents. Another term, namely MT-targeting agents (MTA), is "reserved" for anti-cancer drugs. These are categorised into two classes: (i) MT stabilising agents such as taxanes (paclitaxel/taxol and related drugs), which stabilize GDP-bound tubulin, thereby stabilize the MT, that is, prevent their disassembly, and (ii) MT destabilising agents (e.g. Vinca alkaloids, colchicine, nocodazole and noscapine), which bind to tubulin and cause disassembly. Although some MTA (e.g. paclitaxel in angioplasty) are studied in atherosclerosis therapy, these are not in the scope of present Dance round.

Based on our own results, a paper entitled "Antitubulins - A new therapeutic approach for atherosclerosis?" was published in 1982 (13). Further, we proposed that a search for more "sophisticated" antitubulins aimed at the inhibition of secretory and inflammatory pathway in ASMC is required $(11,14,15)$. This hypothesis was appreciated by other colleagues including in the treatment of patients with atherosclerosis (16-28). 
Noteworthy, in 2012 George Cooper's group has updated their 1993 data (29) demonstrating that the excess presence of MT in cardiomyocytes is important for myocardial contractile dysfunction suggesting that this may be one mechanism contributing to the development of heart failure caused by cardiac hypertrophy (30). The authors also demonstrated that colchicine caused striking improvement in contractile function of cardiomyocytes. Concluding "that chronic beta-adrenergic blockade instituted early might delay or prevent the appearance of the pathological microtubule phenotype".

In brief, the therapeutic use of colchicine has indeed extended beyond gouty arthritis and familial Mediterranean fever. And atherosclerosis emerges as a novel target for antitubulins, a therapy in triplicate, anti-fibrotic, antiproliferative and anti-inflammatory. Moreover, advancement in pharmaceutical design may lead to the production of highly specific biopharmaceuticals targeting key molecules such as MAPs, kinesins, dynein, also caveolin and stathmin (31) involved in the regulation of MT dynamics and related cell functions. Other potential targets might be the membraneassociated tubulin, posttranslational modifications of tubulin, and MT-composed organelles such as centrosome (MTOC $/ \gamma$ TuRC) and non-motile, primary cilia.

\section{QUO VADIS, ASMC?}

\section{To inhibit or to stimulate matrix protein secretion in atherogenesis?}

Modulation of ASMC from contractile to secretory phenotype resulting in matrix protein oversecretion and cell proliferation has, for almost three decades, held center stage in studying atherosclerotic plaque formation (6). These ASMC phenomena were accepted as the major enemy of the artery, as they cause high grade arterial occlusion. However, things changed dramatically in the mid-1990's. Thus the attention was moved from the plaque-associated occlusion toward the integrity of plaque's fibrous cap as a critical factor for the plaque stability (32 and references therein). And, respectively, from decreasing ASMC proliferation and matrix production aimed at vascular occlusion decrease toward increasing ASMC proliferation and matrix production aimed at plaque stabilization, that is, prevention of plaque rupture. The fibrous cap is made up by ASMC-secreted matrix proteins, mostly collagen, a major contributor to the mechanical integrity of the fibrous cap. Basic and clinical studies recognized that human atherosclerotic plaques prone to alterations involving fissuring, erosion, ulceration and rupture of the plaque surface (unstable plaques) usually have fewer ASMC, less collagen fibers, numerous inflammatory cells, and a large lipid-rich core. This insufficiency in ASMC and matrix forms a thin, vulnerable fibrous cap, while ASMC and matrix excess improves fibrous cap's mechanical strength, thus stabilizing the plaque surface (stable plaques).

Hence, until things change again, the secretory phenotype ASMC and their contribution to maintain the stability of plaque's fibrous cap appear to be a "good friend" rather than a potential enemy as previously believed. However, from therapy standpoint, the window remains open: how to achieve the balance between less occlusion of arterial lumen and higher stability of plaque's fibrous cap orchestrated by secretory-state ASMC, the solo fibrogenic cell type of the artery wall (Fig. 1)?

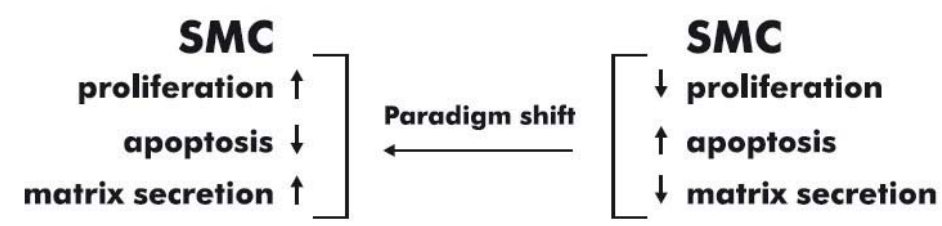

Figure 1. A scheme showing possible ways to modulate atherosclerotic plaque development. Long arrow at the upper part of the figure indicates paradigm shift in our knowledge of atherogenesis-related potential of smooth muscle cells (SMC). Unstable and stable plaque are depicted at the lower part of figure. From (32).

\section{Angioplasty Inflammation $\downarrow$}

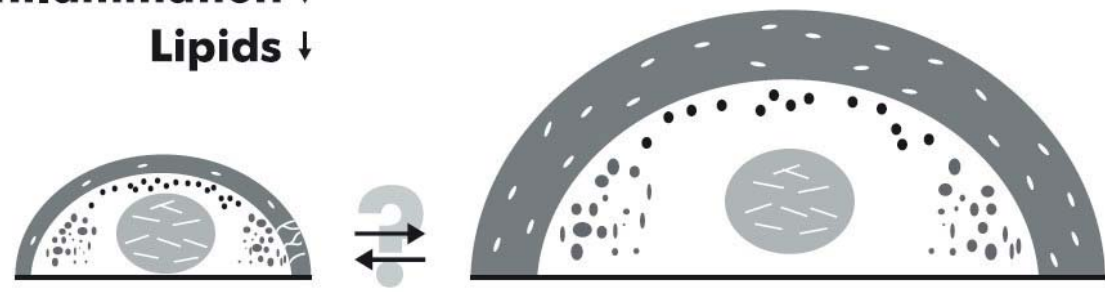

Unstable plaque
Stable plaque 
Further work on molecular and cellular mechanisms of wound-healing phenotypes, including atherosclerotic plaques, keloids and skin, corneal and other ulceration, is required for the better understanding of cell biology of atherosclerotic plaque and its complications. Intriguingly, as demonstrated by Luigi Aloe's research group a potential anti-atherogenic molecule, nerve growth factor (NGF) $(33,34)$, exerts healing effect in corneal ulcers and skin wounds $(35,36)$.

\section{TRACKINS}

\section{$N G F$ and $B D N F$}

Since 1951 when Rita Levi-Montalcini has discovered the first cell growth factor she named nerve growth factor (NGF) (37), the neurotrophins family of proteins has been expending dramatically. This family consists of NGF, proNGF, brain-derived neurotrophic factor (BDNF), pro-BDNF, neurotrophin-3 (NT-3), NT-4/5, NT-6, and NT-7.

Today there is compelling evidence that NGF and BDNF, in addition to its neurotrophic function, influence functions of a large number of non-neuronal cells including immune cells, pancreatic beta cells, cardiomyocytes, endothelial cells, epithelial cells, adipocytes, and cancer cells (reviewed in (38).

\section{NGF, BDNF and Trk receptors: targets for disease therapies}

Neurotrophins mediate their effects via ligation of panneurotrophin receptor, $\mathrm{p} 75^{\mathrm{NTR}}$, and Trk receptors, namely, TrkA ${ }^{N G F}$, Trk B BDNF, Trk B ${ }^{\text {NT-4/5 }}$ (for neurotrophin-4/5), and $\operatorname{TrkC}^{\mathrm{NT}-3}$. The abbreviation Trk stands for tropomyosin receptor kinase or tyrosine receptor kinase (and not „tyrosine kinase receptor" nor „tropomyosin-related kinase“). Binding of neurotrophins to Trk induces receptor dimerization, phosphorylation, and activation of the downstream signaling cascades.

From the abbreviation Trk (pronounced track), we introduce the term trackins - Trk-targeting agents (TTA) that influence positively (agonistically) or negatively (antagonistically) the activity of Trk receptors, focusing on TrkA ${ }^{\mathrm{NGF}}$ and Trk ${ }^{\mathrm{BDNF}}$ in the present Dance round. Noteworthy, transactivation of Trk receptors by G protein-coupled receptor (39) has recently emerged as a novel horizon of neurotrophin actions.

Today, NGF and BDNF are implicated in the pathogenesis of a large spectrum of neuronal and non-neuronal diseases, ranging from Alzheimer's and other neurodegenerative diseases to atherosclerosis and other cardiometabolic diseases. Low levels of local and/or circulating NGF and BDNF were reported in human coronary atherosclerosis (40), metabolic syndrome (41) and acute coronary syndrome (42), suggestive for $(i)$ a role played by NGF and BDNF in the pathogenesis, and (ii) a possible therapeutic effect of TrkA ${ }^{\mathrm{NGF}}$ and TrkB ${ }^{\mathrm{BDNF}}$ receptor agonists in cardiometabolic diseases $(33,34,43,44)$. Also, BDNF is a member of the leptin-mediated anorexigenic circuit in the adipose-brain control of food intake. Conversely, mice heterozygous for targeted disruption of BDNF show hyperphagia and obesity. The same phenotype was observed in mice with a reduced expression of TrkB ${ }^{\mathrm{BDNF}}$ receptor (45).

Noteworthy, brief myocardial ischemia induces a dysfunction of sympathetic cardiac innervation that is accompanied by a rapid increase in NGF release, whereas exogenous administration of NGF protects against such neuronal dysfunction, thus suggesting that the endogenous NGF release is insufficient for complete neural protection (46). Yet, the principle question remains: if NGF is causally related to atherogenesis, is it low or high levels of NGF that are associated with a possible vasculoprotective (atheroprotective) effect?

Further, recent studies demonstrated the therapeutic potential of NGF for ocular and cutaneous diseases $(35,36)$, whereas TrkA ${ }^{\mathrm{NGF}}$ antagonists emerged as novel drugs for pain (47), prostate cancer (48-51), urinary bladder syndromes (52), breast cancer (53). Importantly, tamoxifen prescribed to patients with breast cancer inhibits TrkA ${ }^{\mathrm{NGF}}$ phosphorylation and NGF-induced breast cancer cell proliferation (54). Remembering colchicine and aspirin, tamoxifen data are one of many examples for the discovery of a new action of an old drug.

Note that a pan Trk antagonist, CEP-701, a trademark of Cephalon Inc., West Chester, PA, USA, has been included in some clinical trials for prostate cancer (45). These latter authors demonstrated that $(i)$ TrkA $^{\text {NGF }}$ and TrkB BDNF expression was significantly higher in androgen-negative compared to androgen-positive cells, and (ii) TrkA ${ }^{\text {NGF }}$ and TrkB ${ }^{B D N F}$ expression was positively related to the malignancy and invasion of prostate cancer cells. Also exciting is that intravenous gammaglobulin (IVIg) contains natural antibodies against NGF, and thus is able to inhibit the migration of prostate cancer cells in vitro (51). Currently, several TTA are in ongoing Phase 2 trials with entrectinib and LOXO-101, demonstrating encouraging activity in patients with cancer.

Recent reviews on NGF/TrkA (55) and BDNF/TrkB $(56,57)$ in cancer biology were published. For instance, in neuroblastoma TrkA ${ }^{\mathrm{NGF}}$ expression marks good prognosis, whereas $\operatorname{TrkB}^{\mathrm{BDNF}}$ indicates poor prognosis (56). Another 
"danger" comes from the hypothesis of NGF-induced increased sympathetic nerve sprouting that associates with cardiac arrhythmogenesis and sudden cardiac death (58, $58 \mathrm{a}$ ). Note that one of us (LA) found recently that nasal administration of high-pressure isotonic physiological saline solution enhanced not only NGF levels and the expression of NGF receptors but also the tumor suppressor protein p73 in human brain cancer tissue, thus excluding any cancerogenic action of NGF itself (data in press).

In cardiometabolic and neuropsychiatric diseases, NGF- and BDNF-based therapeutic approaches may include (i) targeting the secretory and signaling pathways using existing or novel drugs (59), (ii) TrkB $^{\mathrm{BDNF}}$ transactivation (39), and (iii) transgenic mice with Alzheimer's disease fed J147, a new compound, in diet improve their memory correlated with reduced soluble levels of beta-amyloid and increased hippocampal levels of NGF and BDNF (60). Likewise, a dipeptide mimetic of NGF, causing phosphorylation of TrkA ${ }^{\mathrm{NGF}}$, was reported to be efficient in animal models of Alzheimer's and Parkinson's disease as well as ischemic and hemorrhagic stroke (61 and references therein for other examples of TrkA ${ }^{\mathrm{NGF}}$ agonists). These authors also demonstrated that another dipeptide, noopept, increase the expression of mRNA ${ }^{\mathrm{NGF}}$ and $\mathrm{mRNA}^{\mathrm{BDNF}}$ in rat hippocampus (62).

Moreover, neurodegenerative hypothesis of depression is based on decreased hippocampal level of BDNF, NGF and NT-3 in patients with depression. Accordingly, biogenic amine-based antidepressants as well as glutamate-based drugs such as the NMDA antagonist ketamine increase synthesis of BDNF and activate TrkB ${ }^{\mathrm{BDNF}}$ signaling pathway, and the antidepressant effects of these molecules are abolished in BDNF deficient mice (63-66). Intriguingly, high-pressure administration of sterile physiological saline isotonic solution into nasal cavity of patients with sensorineural hearing loss and tinnitus enhances NGF level (in the nasal fluid) leading to improvement of hearing (67). "Paradoxically", recent experimental results obtained with a TrkA ${ }^{\mathrm{NGF}}$ inhibitor, GW441756, suggest that one component of an optimal therapy for Alzheimer's disease may be a TrkA ${ }^{\mathrm{NGF}}$ antagonist (68).

\section{CODA}

Further studies should provide additional answers to the question of how the dysfunction of tubulin-MT and NGF$\operatorname{Trk}^{\mathrm{NGF}}$ and BDNF-TrkB ${ }^{\mathrm{BDNF}}$ is involved in the pathogenesis of cardiometabolic, oncologic, neuropsychiatric and other diseases. This may help to construct a conceptually novel therapeutic frame for future studies on antitubulins as well as TTA, herein designated trackins. Moreover, TrkA ${ }^{\mathrm{NGF}}$ and MT "hug" each other in membrane lipid rafts, NGF favoring this interaction (69; for other examples of similar associations, see 70-75). This may be a promising crossroad of MT and Trk.

Consequently, antitubulins and trackins we Dance round might be two challenges that promise reward in basic, translational and clinical research.

\section{Conflict of interest statement}

The authors have no conflicts of interest.

\section{ACKNOWLEDGMENTS}

We thank our brain-and-heart friends (BHF) Federica Sornelli, Vesselka Nikolova, Stoyan Stoev, Gorana Rančić, Neşe Tunçel, Marcia Hiriart and Jerzy Beltowsky for their cooperation in our common studies on NGF, BDNF and adipose tissue. We apologize to the authors of many relevant articles that were not quoted here for reasons of brevity.

\section{REFERENCES}

1. Fletcher DA, Mullins RD. Cell mechanics and the cytoskeleton. Nature 2010; 463: 485-492. [DOI: 10.1038/ nature08908]

2. Hirokawa N. Kinesin and dynein superfamily proteins and the mechanism of organelle transport. Science 1998; 279: 519. [DOI: 10.1126/science.279.5350.519]

3. Hancock WO. Bidirectional cargo transport: moving beyond tug of war. Nat Rev Mol Cell Biol 2014; 15: 615628. [DOI: 10.1038/nrm3853]

4. Cui J, Pang J, Lin YJ, Jiang P, Gong H, Wang Z, et al. Conventional kinesin KIF5B mediates adiponectin secretion in 3T3-L1 adipocytes. Biochem Biophys. Res Commun 2016; 476: 620-626. [DOI: 10.1016/j. bbrc.2016.06.008]

5. Fu MM, Holzbaur EL. Integrated regulation of motordriven organelle transport by scaffolding proteins. Trends Cell Biol 2014; 24: 564-574. [DOI: 10.1016/j. tcb.2014.05.002]

6. Ross R. Atherosclerosis - an inflammatory disease. $N$ Engl J Med 1999; 340: 115-126. [DOI: 10.1056/ NEJM199901143400207]

7. Chaldakov GN, Fiore M, Ghenev PI, Stankulov IS, Aloe L. Atherosclerotic lesions: possible interactive involvement of intima, adventitia and associated adipose tissue. Int Med J 2000; 7: 43-49. 
8. Chaldakov GN. Human body as a multicrine system, with special reference to cell protein secretion: From vascular smooth muscles to adipose tissue. Biomed Rev 2016; 27: VIII-XIX.

9. Chaldakov GN, Nikolov SD. Ultrastructure of the arterial smooth muscle cell. In: Wolf S and Werthessen NT, editors. The Smooth Muscle of the Artery. Springer US, Boston, MA, 1975; 14-20

10. Chaldakov GN, Vankov VN. Morphological aspects of secretion in the arterial smooth muscle cell, with special reference to the Golgi complex and microtubular cytoskeleton. Atherosclerosis 1986; 61: 175-192. [DOI: 10.1016/0021-9150(86)90137-1]

11. Chaldakov GN and Vankov VN, Antifibrotic approach in the therapy of arterial occlusive diseases: new considerations. In: Trubestein G, editor. Conservative Therapy of Arterial Occlusive Disease. 1986; Georg Thieme Verlag. pp. 224-226.

12. Zhu X, Efimova N, Arnette C, Hanks SK, Kaverina I. Podosome dynamics and location in vascular smooth muscle cells require CLASP-dependent microtubule bending. Cytoskeleton (Hoboken.) 2016; 73: 300-315. [DOI: $10.1002 / \mathrm{cm} .21302]$

13. Chaldakov GN. Antitubulins - a new therapeutic approach for atherosclerosis? Atherosclerosis 1982; 44: 385-390. [DOI: 10.1016/0021-9150(82)90013-2]

14. Chaldakov GN. Anti-inflammatory drugs and ischemic heart disease: new considerations (a cell biologist's proposal to cardiologists). J Am Coll Cardiol 1991; 17: 1445-1446. [DOI: 10.1016/S0735-1097(10)80161-5]

15. Chaldakov GN. Proposal for clinical trials using antiinflammatory drugs in the therapy of angina pectoris, myocardial infarction and coronary restenosis after angioplasty and bypass grafting. Med Hypotheses 1992; 37: 74-75. [DOI: 10.1016/0306-9877(92)90043-C]

16. Lu Y, Chen J, Xiao M, Li W, Miller DD. An overview of tubulin inhibitors that interact with the colchicine binding site. Pharm Res 2012; 29: 2943-2971. [DOI: 10.1007/ s11095-012-0828-z]

17. Nidorf M, Thompson PL. Effect of colchicine $(0.5$ $\mathrm{mg}$ twice daily) on high-sensitivity $\mathrm{C}$-reactive protein independent of aspirin and atorvastatin in patients with stable coronary artery disease. Am J Cardiol 2007; 99: 805-807. [DOI: 10.1016/j.amjcard.2006.10.039]

18. Nidorf SM, Eikelboom JW, Budgeon CA, Thompson PL. Low-Dose Colchicine for Secondary Prevention of
Cardiovascular Disease. J Am Coll Cardiol 2013; 61: 404. [DOI: 10.1016/j.jacc.2012.10.027]

19. Huang C, Cen C, Wang C, Zhan H, Ding X. Synergistic effects of colchicine combined with atorvastatin in rats with hyperlipidemia. Lipids Health Dis 2014; 13: 67. [DOI: 10.1186/1476-511X-13-67]

20. Leung YY, Yao Hui LL, Kraus VB. Colchicine--Update on mechanisms of action and therapeutic uses. Semin. Arthritis Rheum 2015; 45: 341-350. [DOI: 10.1016/j. semarthrit.2015.06.013]

21. Robertson S, Martinez GJ, Payet CA, Barraclough JY, Celermajer DS, Bursill C, et al. Colchicine therapy in acute coronary syndrome patients acts on caspase- 1 to suppress NLRP3 inflammasome monocyte activation. Clin Sci (Lond) 2016; 130: 1237-1246. [DOI: 10.1042/ CS20160090]

22. Martinez GJ, Robertson S, Barraclough J, Xia Q, Mallat Z, Bursill C, et al. Colchicine acutely suppresses local cardiac production of inflammatory cytokines in patients with an acute coronary syndrome. J Am Heart Assoc 2015; 4: e002128. [DOI: 10.1161/JAHA.115.002128]

23. Khan R, Spagnoli V, Tardif JC, L'Allier PL. Novel antiinflammatory therapies for the treatment of atherosclerosis. Atherosclerosis 2015; 240: 497-509. [DOI: 10.1016/j. atherosclerosis.2015.04.783]

24. Tousoulis D, Oikonomou E, Economou EK, Crea F, Kaski JC. Inflammatory cytokines in atherosclerosis: current therapeutic approaches. Eur Heart J2016; 37: 1723-1732. [DOI: 10.1093/eurheartj/ehv759]

25. Bauriedel G, Heimerl J, Beinert T, Welsch U, Hofling B. Colchicine antagonizes the activity of human smooth muscle cells cultivated from arteriosclerotic lesions after atherectomy. Coron Artery Dis 1994; 5: 531-539.

26. Wojcicki J, Hinek A, Jaworska M, Samochowiec L. The effect of colchicine on the development of experimental atherosclerosis in rabbits. Pol.J Pharmacol Pharm 1986; 38: 343-348.

27. Wegrowski J, Moczar M, Lagrue G, Rhabar K, Robert AM, Robert L. Effect of colchicine on atherosclerosis. II. Biochemical studies on skin biopsies from patients treated perorally with colchicine. Clin Physiol Biochem 1985; 3: 226-233.

28. Lagrue G, Wegrowski J, Rhabar K, Meyer-Heine A, Balanger S, Robert AM, et al. Effect of colchicine on atherosclerosis. I. Clinical and biological studies. Clin Physiol Biochem 1985; 3: 221-225. 
29. Tsutsui H, Ishihara K, Cooper G. Cytoskeletal role in the contractile dysfunction of hypertrophied myocardium. Science 1993; 260: 682. [DOI: 10.1126/science.8097594]

30. Cheng G, Kasiganesan H, Baicu CF, Wallenborn JG, Kuppuswamy D, Cooper G. Cytoskeletal role in protection of the failing heart by beta-adrenergic blockade. $\mathrm{Am} \mathrm{J}$ Physiol Heart Circ Physiol 2012; 302: H675-H687. [DOI: 10.1152/ajpheart.00867.2011]

31. Kawabe Ji, Okumura S, Nathanson MA, Hasebe N, Ishikawa Y. Caveolin regulates microtubule polymerization in the vascular smooth muscle cells. Bioch Biophys Res Commun 2006; 342: 164-169.

32. Chaldakov GN, Fiore M, Ghenev PI, Stankulov IS, Angellucci F, Pavlov PS, et al. Conceptual novelties in atherogenesis: Smooth muscle cells, adventitia, and adipose tissue. Biomed Rev 2000; 11, 63-67.

33. Chaldakov GN, Fiore M, Stankulov IS, Manni L, Hristova $\mathrm{MG}$, Antonelli A, et al. Neurotrophin presence in human coronary atherosclerosis and metabolic syndrome: a role for NGF and BDNF in cardiovascular disease? Prog. Brain Res 2004; 146: 279-289. [DOI: 10.1016/S00796123(03)46018-4]

34. Chaldakov GN, Fiore M, Tonchev AB, Aloe L. Adipopharmacology, a novel drug discovery approach: a metabotrophic perspective. Lett Drug Design Discov 2006; 3: 503-505.

35. Lambiase A, Rama P, Bonini S, Caprioglio G, Aloe L. Topical treatment with nerve growth factor for corneal neurotrophic ulcers. N Engl J Med 1998; 338: 1174-1180. [DOI: 10.1056/NEJM199804233381702]

36. Aloe L, Tirassa P, Lambiase A. The topical application of nerve growth factor as a pharmacological tool for human corneal and skin ulcers. Pharmacol Res 2008; 57: 253-258. [DOI: 10.1016/j.phrs.2008.01.010]

37. Levi-Montalcini R. The nerve growth factor 35 years later. Science 1987; 237: 1154-1162. [DOI: 10.1126/science.3306916]

38. Aloe L, Chaldakov GN. The multiple life of nerve growth factor: tribute to rita levi-montalcini (1909-2012). Balkan Med J 2013; 30: 4-7. [DOI: 10.5152/balkanmedj.2013.003]

39. Jeanneteau F, Chao MV. Promoting neurotrophic effects by GPCR ligands. Novartis Found Symp 2006; 276: 181 189. [DOI: 10.1002/9780470032244.ch14]

40. Chaldakov GN, Stankulov IS, Fiore M, Ghenev PI, Aloe L. Nerve growth factor levels and mast cell distribution in human coronary atherosclerosis. Atherosclerosis 2001;
159: 57-66. [DOI: 10.1016/S0021-9150(01)00488-9]

41. Geroldi D, Minoretti P, Emanuele E. Brain-derived neurotrophic factor and the metabolic syndrome: more than just a hypothesis. Med Hypotheses 2006; 67: 195-196. [DOI: 10.1016/j.mehy.2006.02.001]

42. Manni L, Nikolova V, Vyagova D, Chaldakov GN, Aloe L. Reduced plasma levels of NGF and BDNF in patients with acute coronary syndromes. Int J Cardiol 2005; 102: 169-171. [DOI: 10.1016/j.ijcard.2004.10.041]

43. Yanev SG, Aloe L., Fiore M., Chaldakov G. N. Neurotrophic and metabotrophic potential of nerve growth factor and brain-derived neurotrophic factor: Linking cardiometabolic and neuropsychiatric diseases. World $J$ Pharmacol 2013; 2: 92-99. DOI: 10.5497/wjp.v2.i4.92

44. Schulte-Herbruggen O, Braun A, Rochlitzer S, JockersScherubl MC, Hellweg R. Neurotrophic factors - a tool for therapeutic strategies in neurological, neuropsychiatric and neuroimmunological diseases? Curr Med Chem 2007; 14: 2318-2329. [DOI: 10.2174/092986707781745578]

45. Bariohay B, Lebrun B, Moyse E, Jean A. Brain-derived neurotrophic factor plays a role as an anorexigenic factor in the dorsal vagal complex. Endocrinology 2005; 146: 5612-5620. [DOI: 10.1210/en.2005-0419]

46. Abe T, Morgan DA, Gutterman DD. Protective role of nerve growth factor against postischemic dysfunction of sympathetic coronary innervation. Circulation 1997; 95: 213-220. [DOI: 10.1161/01.CIR.95.1.213]

47. Hirose M, Kuroda Y, Murata E. NGF/TrkA Signaling as a Therapeutic Target for Pain. Pain Pract. 2016; 16: 175182. [DOI: 10.1111/papr.12342]

48. Weeraratna AT, Arnold JT, George DJ, DeMarzo A, Isaacs JT. Rational basis for Trk inhibition therapy for prostate cancer. Prostate 2000; 45: 140-148. [DOI: 10.1002/1097-0045(20001001)45:2\%3C140::AIDPROS8\%3E3.0.CO;2-\%23]

49. Festuccia C, Muzi P, Gravina GL, Millimaggi D, Speca S, Dolo V, et al. Tyrosine kinase inhibitor CEP-701 blocks the NTRK1/NGF receptor and limits the invasive capability of prostate cancer cells in vitro. Int J Oncol. 2007; 30: 193-200. [DOI: 10.3892/ijo.30.1.193]

50. Anagnostopoulou V, Pediaditakis I, Alkahtani S, Alarifi SA, Schmidt EM, Lang F, et al. Differential effects of dehydroepiandrosterone and testosterone in prostate and colon cancer cell apoptosis: the role of nerve growth factor (NGF) receptors. Endocrinology 2013; 154: 2446-2456. [DOI: 10.1210/en.2012-2249] 
51. Warrington RJ, Lewis KE. Natural antibodies against nerve growth factor inhibit in vitro prostate cancer cell metastasis. Cancer Immunol.Immunother. 2011; 60: 187195. [DOI: 10.1007/s00262-010-0934-x]

52. Seth JH, Sahai A, Khan MS, van der Aa F, de RD, Panicker $J \mathrm{~N}$, et al. Nerve growth factor (NGF): a potential urinary biomarker for overactive bladder syndrome (OAB)? BJU.Int 2013; 111: 372-380. [DOI: 10.1111/j.1464410X.2012.11672.x]

53. Chakravarthy R, Mnich K, Gorman AM. Nerve growth factor (NGF)-mediated regulation of p75(NTR) expression contributes to chemotherapeutic resistance in triple negative breast cancer cells. Biochem Biophys. Res Commun. 2016; 478: 1541-1547. [DOI: 10.1016/j. bbrc.2016.08.149]

54. Chiarenza A, Lazarovici P, Lempereur L, Cantarella G, Bianchi A, Bernardini R. Tamoxifen inhibits nerve growth factor-induced proliferation of the human breast cancerous cell line MCF-7. Cancer Res 2001; 61: 3002-3008.

55. Aloe L, Rocco ML, Balzamino BO, Micera A. Nerve growth factor: role in growth, differentiation and controlling cancer cell development. J Exp.Clin Cancer Res 2016; 35: 116. [DOI: 10.1186/s13046-016-0395-y]

56. Thiele CJ, Li Z, McKee AE. On Trk--the TrkB signal transduction pathway is an increasingly important target in cancer biology. Clin Cancer Res 2009; 15: 5962-5967. [DOI: 10.1158/1078-0432.CCR-08-0651]

57. De la Cruz-Morcillo MA, Berger J, Sanchez-Prieto R, Saada S, Naves T, Guillaudeau A, et al. p75 neurotrophin receptor and pro-BDNF promote cell survival and migration in clear cell renal cell carcinoma. Oncotarget. 2016; 7: 34480-34497. [DOI: 10.18632/ oncotarget.8911]

58. Cao JM, Chen LS, KenKnight BH, Ohara T, Lee MH, Tsai $\mathrm{J}$, et al. Nerve sprouting and sudden cardiac death. Circ. Res 2000; 86: 816-821. [DOI: 10.1161/01.RES.86.7.816]

58a. Bloom HL. Beyond beta-blockade: Nerve growth factor and arrhythmia. Heart Rhythm 2007; 4: S437-S448. [DOI: 10.1016/j.hrthm.2007.06.017]

59. Kozisek ME, Middlemas D, Bylund DB. Brain-derived neurotrophic factor and its receptor tropomyosin-related kinase B in the mechanism of action of antidepressant therapies. Pharmacol Ther 2008; 117: 30-51. [DOI: 10.1016/j.pharmthera.2007.07.001]

60. Prior M, Dargusch R, Ehren JL, Chiruta C, Schubert D. The neurotrophic compound $\mathrm{J} 147$ reverses cognitive impairment in aged Alzheimer's disease mice. Alzheimers Res Ther 2013; 5: 25. [DOI: 10.1186/alzrt179]

61. Povarnina PY, Vorontsova ON, Gudasheva TA, Ostrovskaya RU, Seredenin SB. Original nerve growth factor mimetic dipeptide GK-2 restores impaired cognitive functions in rat models of Alzheimer's disease. Acta Naturae 2013; 5: 84-91.

62. Ostrovskaya RU, Gudasheva TA, Zaplina AP, Vahitova JV, Salimgareeva MH, Jamidanov RS, et al. Noopept stimulates the expression of NGF and BDNF in rat hippocampus. Bull Exp Biol Med 2008; 146: 334-337.

63. Lang UE, Borgwardt S. Molecular mechanisms of depression: perspectives on new treatment strategies. Cell Physiol Biochem 2013; 31: 761-777. [DOI: 10.1159/000350094]

64. Zhen YF, Zhang J, Liu XY, Fang H, Tian LB, Zhou DH, et al. Low BDNF is associated with cognitive deficits in patients with type 2 diabetes. Psychopharmacology (Berl) 2013; 227: 93-100. [DOI: 10.1007/s00213-0122942-3]

65. Akinfiresoye L, Tizabi Y. Antidepressant effects of AMPA and ketamine combination: role of hippocampal BDNF, synapsin, and mTOR. Psychopharmacology (Berl) 2013; 230: 291-298. [DOI: 10.1007/s00213-013-3153-2 ]

66. Jiang C, Salton SR. The role of neurotrophins in major depressive disorder. Transl Neurosci 2013; 4: 46-58. [DOI: 10.2478/s13380-013-0103-8]

67. Salvinelli F, Frari V, Rocco ML, Rosso P, Aloe L. Enhanced presence of NGF and mast cells number in nasal cavity after autologous stimulation: relation with sensorineural hearing deficit. Eur.Rev Med Pharmacol Sci 2015; 19: 381-391.

68. Zhang Q, Descamps O, Hart MJ, Poksay KS, Spilman P, Kane DJ, et al. Paradoxical effect of TrkA inhibition in Alzheimer's disease models. J Alzheimers Dis 2014; 40: 605-617. [DOI: 10.3233/JAD-130017]

69. Pryor S, McCaffrey G, Young LR, Grimes ML. NGF causes TrkA to specifically attract microtubules to lipid rafts. PLoS One 2012; 7: e35163. [DOI: 10.1371/journal. pone.0035163]

70. Farina AR, Di Ianni N, Cappabianca L, Ruggeri P, Ragone M, Ianni G, et al. TrkAIII promotes microtubule nucleation and assembly at the centrosome in SH-SY5Y neuroblastoma cells, contributing to an undifferentiated anaplastic phenotype. Biomed Res Int 2013; 2013: 740187. DOI: $10.1155 / 2013 / 740187$ 
71. Sierra-Fonseca JA, Najera O, Martinez-Jurado J, Walker EM, Varela-Ramirez A, Khan AM, et al. Nerve growth factor induces neurite outgrowth of PC12 cells by promoting G $\beta \gamma$-microtubule interaction. BMC Neurosci 2014; 15: 132. DOI: 10.1186/s12868-014-0132-4

72. Ketschek A, Jones S, Spillane M, Korobova F, Svitkina T, Gallo G. Nerve growth factor promotes reorganization of the axonal microtubule array at sites of axon collateral branching. Dev Neurobiol 2015; 75: 1441-1461. DOI: 10.1002/dneu.22294

73. Han YM, Kang GM, Byun K, Ko HW, Kim J, Shin MS, et al. Leptin-promoted cilia assembly is critical for normal energy balance. J Clin Invest 2014; 124: 2193-2197. DOI: 10.1172/JCI69395.

74. Chaldakov GN, Dikranian K. NGF-PC-AD connection. Adipobiology 2013; 5: 19-22.

75. Chakravarthy B, Gaudet C, Menard M, Atkinson T, Chiarini A, Dal Pra I, et al. The p75 neurotrophin receptor is localized to primary cilia in adult murine hippocampal dentate gyrus granule cells. Biochem Biophys Res Commun 2010; 401:458-462. DOI: 10.1016/j.bbrc.2010.09.081 